\title{
New Health Sciences Descriptors to classify and retrieve information on equity*
}

\author{
Ana Cristina Espíndola Campos ${ }^{1}$, Arthur Treuherz' ${ }^{1}$, Renato Toshiyuki Murasaki ${ }^{1}$, Diego Gonzalez ${ }^{1}$ \\ and Oscar J Mújica²
}

Suggested citation Campos ACE, Treuherz A, Murasaki RT, Gonzalez D, Mújica OJ. New Health Sciences Descriptors to classify and retrieve information on equity. Rev Panam Public Health. 2021;45:e78. https://doi.org/10.26633/RPSP.2021.78

ABSTRACT The Health Sciences Descriptors (DeCS) vocabulary establishes a unique and common language that allows the organization and facilitates the search and retrieval of technical and scientific literature on health available in the information sources of the Virtual Health Library. The DeCS, created by the Latin American and Caribbean Center on Health Sciences Information (BIREME), a specialized center of the Pan American Health Organization/World Health Organization (PAHO/WHO), is the translation and extension of the Medical Subject Headings (MeSH) vocabulary, maintained by the United States National Library of Medicine. BIREME, in coordination with experts from Latin America and the Caribbean, has included in the DeCS the topics of equity, gender, ethnicity and human rights - cross-cutting themes in the programmatic framework of $\mathrm{PAHO} / \mathrm{WHO}$ technical cooperation - to ensure better retrieval and use of scientific information and evidence related to these topics. The objective of this article is to describe the methodology used during the terminology review of the DeCS and to report the results obtained and the impacts of the terminology expansion in the field of equity, which included the inclusion of 35 new descriptors.

Keywords $\quad$ Equity; information systems; Medical Subject Headings; evidence-based practice; access to information.

The use of controlled vocabularies establishes a unique language that allows the organization and facilitates the search and retrieval of information, making possible its description and indexing through the use of related terminological concepts in a specific area of knowledge. The structured, multilingual Health Sciences Descriptors (DeCS) vocabulary (1) plays this role for technical and scientific literature on health available in the main information sources of the Virtual Health Library, integrating the LILACS methodology (2).

The origin of the DeCS dates back to the late 1970s, when the Latin American and Caribbean Center on Health Sciences Information (BIREME), a specialized center of the Pan American Health Organization/World Health Organization (PAHO/ WHO), began collaborating with the United States National
Library of Medicine (NLM) to translate the Medical Subject Headings (MeSH) vocabulary into Portuguese and Spanish. Having identified the need to expand the terminology offered by the NLM, BIREME began to develop and maintain the Science and Health, Homeopathy, Public Health, and Health Surveillance categories in three languages in a manner integrated and compatible with the MeSH. The 2019 version of DeCS has 33,966 descriptors and qualifiers, of which 29,431 come from the MeSH and 4,535 are exclusively DeCS.

There are multiple challenges related to the organization and retrieval of relevant information, given the exponential growth in available information. Controlled vocabularies are essential for overcoming these challenges. During the annual DeCS updates following the annual MeSH updates, and on

\footnotetext{
* Official English translation from the original Spanish manuscript made by the Pan American Health Organization. In case of discrepancy, the original version shall prevail. Access to original manuscript: https://doi.org/10.26633/ RPSP.2020.98
}

\footnotetext{
Latin American and Caribbean Center on Health Sciences Information, Pan American Health Organization. São Paulo, Brazil. $\triangle$ Ana Cristina Espíndola Campos, camposan@paho.org.

2. Pan American Health Organization, Washington, D.C., United States of America.
} 
other occasions, BIREME has promoted terminology evaluation studies with the NLM, proposing changes to the MeSH and providing feedback on the DeCS's own exclusive categories.

BIREME's alignment with PAHO's technical cooperation activities and programs revealed the need to assess DeCS coverage for the four cross-cutting dimensions that contextualize the social determinants of health approach: equity (3), gender, ethnicity, and human rights. These dimensions express the commitment to reducing health inequalities, recognized by PAHO/ WHO in its 2020-2025 Strategic Plan: Equity at the Heart of Health (4). For optimal organization, search, and retrieval of information related to these cross-cutting topics, BIREME developed a methodology for evaluating terminology representativeness in the DeCS/MeSH (5) and proposing its extension through the mapping and analysis of vocabularies and existing reference documents. Promoting health equity is at the heart of PAHO's mission and is a fundamental principle for health policy action (6). In recent years, health equity has gained high visibility and global relevance, as reflected in the exponential expansion of the issue - especially social inequalities in health in the global and regional scientific literature (6). In this context, maximizing the specific capacity to retrieve this information is a priority. The goal of this article is to describe the methodology for DeCS terminology review on the topic of health equity and to assess the impacts of including 35 new descriptors in the 2019 version of the DeCS.

\section{MATERIALS AND METHODOLOGY}

The methodology for identifying and expanding the representation of equity in the DeCS/MeSH had five steps:

Step 1. Analyze the representativeness of the term "equity" in the DeCS/MeSH. The first activity was to identify existing terms in the DeCS that included the word "equity" in Spanish, Portuguese, or English. This was done with the Boolean search equidad OR equidade OR equity in the descriptor, synonym, or historical fields of the DeCS/MeSH database. The terms found were listed, then those not related to equity or that had more than one meaning and would therefore result in the retrieval of documents not related to equity were deleted. Second, the specific descriptors of the hierarchical branches of those terms previously found through searches in the DeCS/MeSH hierarchical index were identified. The terms found were added to those obtained in the first activity. Lastly, search expressions were generated for each DeCS/MeSH concept found in the previous activities, including the descriptor and its synonyms in all three languages, executed in the Virtual Health Library information sources in its search interface. Search expressions followed the pattern "descriptor in English" OR "descriptor in Spanish" OR "descriptor in Portuguese" OR "synonym 1 in English" OR "synonym 1 in Spanish" OR "synonym 1 in Portuguese" OR X, where $X$ is the Boolean expression OR of all synonyms of a descriptor, in all three languages. Each search expression generated is part of a single expression, combined with the OR operator, so that related documents in the Virtual Health Library can be retrieved.

Step 2. Search for equity-related vocabularies. Google searches were done for equity vocabularies using the search expression (tesaur* OR thesaur* OR taxonom* OR vocabul* OR dicionário* OR dictionar ${ }^{*}$ OR diccionario* OR glossário* OR glosario* OR glossary) AND (Equidad* OR Equity). The vocabularies were selected based on (a) the order in which they appeared in the search results; (b) the type of institution associated with publication of the vocabulary (international organizations, governments, universities, foundations, non-governmental organizations, etc.); (c) the structure of the terms, with preference for taxonomies, thesauruses and hierarchical classifications; (d) preference for nouns, avoiding jargon, although some adjectives were included as alternative terms for the respective nouns when their use was entrenched in that area; (e) selection of vocabularies in English, Spanish, and Portuguese, in accordance with BIREME's area of work with the DeCS / MeSH; and (f) availability, for free, of the full text of the reference documents. The terms found in the vocabularies identified in the previous activity that were directly related to equity were then selected. Lastly, the preferred terms were translated, grouped conceptually, and selected, classifying them as a DeCS/MeSH descriptor or synonym.

Step 3. Identify more descriptors and perform a quantitative comparison of retrieved documents. Documents were retrieved from the Virtual Health Library based on the search expression resulting from the combination of terms found in steps 1 and 2, using the OR operator, and the number of documents retrieved was compared with the search results from step 1 to identify the representativeness of the terms from other vocabularies in the Virtual Health Library and quantify the extent to which their use has expanded document retrieval capacity. Lastly, other DeCS/MeSH descriptors used in indexing the documents retrieved in the previous activity through the analysis of the "main subject" filter that are available in the Virtual Health Library search interface were identified. A qualitative analysis of the results obtained using this filter provided other descriptors relevant to the broader research on the subject.

Step 4. Propose new descriptors to the existing hierarchy. The new concepts identified in the previous steps and the possibility of incorporating them into the DeCS/MeSH hierarchy were analyzed, in line with the hierarchical codes and the scope specifications for the new terms. This work was limited to the categories exclusive to the DeCS, managed by BIREME. Those terms that could also be incorporated into the MeSH categories were suggested to the NLM terminology team.

Step 5. Experts review the terminology expansion proposal. The proposal for inclusion of new descriptors was submitted to experts in the field, including professionals at the national and international level, through PAHO/WHO Regional Advisors. The expert group evaluated the proposal and sent BIREME its opinion on the new descriptors, which was considered in the final $\mathrm{DeCS} / \mathrm{MeSH}$ update process.

\section{RESULTS AND DISCUSSION}

Step 1 identified 28 equity-related descriptors already in the DeCS/MeSH: culturally competent care; equity; equity in access; equity in coverage; equity in resource allocation; equity in water access; family health strategy; gender and health; global health; health care; health care resource allocation; health equity; health indicators; health inequalities; health services accessibility; health status disparities; health systems; 
healthcare disparities; population education; quality indicators; quality of health care; social conditions; social inequity; social investment projects; social justice; social marginalization; socioeconomic factors; sustainable development goals; and women's rights. Using these $28 \mathrm{DeCS} / \mathrm{MeSH}$ descriptors, 734,444 documents available in the Virtual Health Library were retrieved in June 2017.

In step 2, 14 information sources (8-21) were identified through Google resulting in the selection of 139 terms, 91 of which were already represented in the DeCS/MeSH or could be added as synonyms.

In step 3, 748,041 documents were retrieved from the Virtual Health Library, and an analysis of the "main subject" filter identified 12 more descriptors. After analyzing the terms found, in step 4 it was proposed that 44 new terms be added.

Lastly, in step 5, the experts removed 11 descriptors and proposed 6 . Of these 6 , those that were not very specific or already existed in the DeCS were eliminated. The end result was the addition of 35 terms as new descriptors in categories exclusive to the DeCS (Table 1). When considering all new equity-related descriptors and synonyms, the majority were in the Public Health category, which is to be expected since that is where BIREME is engaged (Figure 1).

A further 44 terms were added as synonyms of the proposed new descriptors or existing descriptors, including in the $\mathrm{MeSH}$ categories: collaboration for health promotion; community action for health; economic and social policy inequity; economic policy inequity; ethnic health disparities; expected years of school; financial health disparities; gender health disparities; gender health equity; gender-sensitive indicator; health care equity; health citizenship; health gain; health goals; health inequality monitoring; health inequality reports; health investment; health outcomes; health promotion evaluation; health promotion infrastructure; health promotion outcomes; health status analysis; health status indicators; health system performance indicators; health targets; healthy environments; healthy public policy; human development index; impartial health policies; innovations; intermediate health outcomes;

TABLE 1. New equity-related descriptors

\begin{tabular}{|c|c|}
\hline New equity descriptors & Broader descriptor \\
\hline \multicolumn{2}{|l|}{ Chronic disease indicators } \\
\hline \multicolumn{2}{|l|}{ Cognitive social capital } \\
\hline Community health indicators & Health indicators \\
\hline Composite indicators & Socioeconomic factors \\
\hline \multicolumn{2}{|l|}{ Concentration index } \\
\hline \multicolumn{2}{|l|}{ Contextual effects of health inequalities } \\
\hline \multicolumn{2}{|l|}{ Cumulative effects of health inequalities } \\
\hline \multicolumn{2}{|l|}{ Declaration of Alma-Ata } \\
\hline \multicolumn{2}{|l|}{ Dissimilarity index } \\
\hline Eco-epidemiology & Ecological studies \\
\hline Equity stratifiers & Health equity \\
\hline Gini coefficient & Development indicators \\
\hline Gradient inequality index & Health status \\
\hline \multicolumn{2}{|l|}{ Health development } \\
\hline Health empowerment & Health promotion \\
\hline \multicolumn{2}{|l|}{ Health expectancy } \\
\hline \multicolumn{2}{|l|}{ Health gains } \\
\hline \multicolumn{2}{|l|}{ Health inequality indicators } \\
\hline \multicolumn{2}{|l|}{ Health inequality monitoring } \\
\hline Health observatories & Health inequality monitoring \\
\hline \multicolumn{2}{|l|}{ Horizontal equity } \\
\hline \multicolumn{2}{|l|}{ Latent effects of health inequalities } \\
\hline \multicolumn{2}{|l|}{ Negative social capital } \\
\hline Network social capital & Social capital \\
\hline Pathway effects of health inequalities & Health status disparities \\
\hline Per capita gross national product & Per capita income \\
\hline Population attributable risk & Rates, ratios, and proportions \\
\hline \multicolumn{2}{|l|}{ Public anti-discrimination policies } \\
\hline Social cohesion & Sociological factors \\
\hline Social epidemiology & Epidemiological studies \\
\hline \multicolumn{2}{|l|}{ Social vulnerability index } \\
\hline \multicolumn{2}{|l|}{ Socioeconomic gradient in health } \\
\hline Tracer indicators & Health inequality indicators \\
\hline Universal health coverage & Health services accessibility \\
\hline Vertical equity & \\
\hline
\end{tabular}


FIGURE 1. Percentage distribution of the 35 new equity-related descriptors and synonyms by DeCS/MeSH category

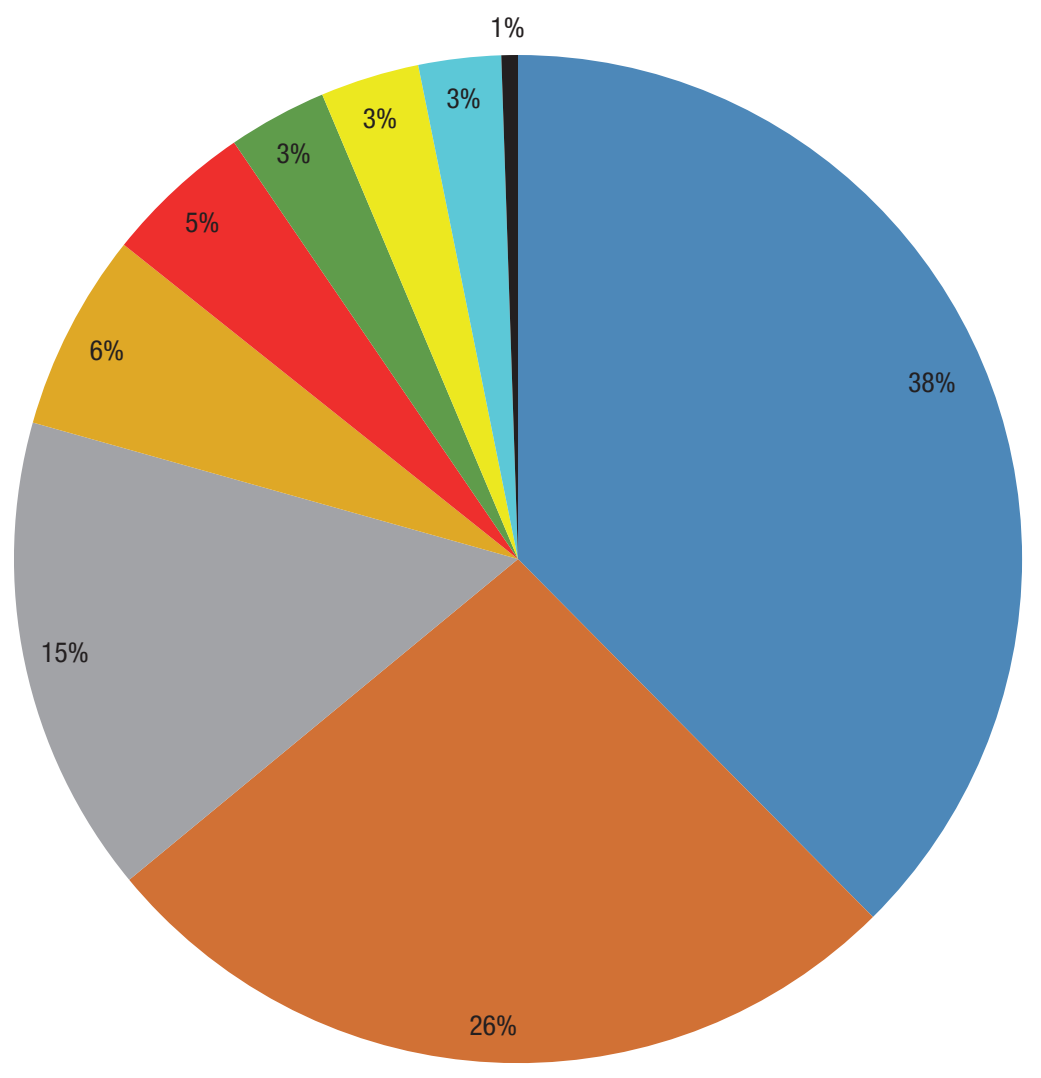

Public health

Health care

Anthropology, Education, Sociology, and Social Phenomena

Health surveillance

Disciplines and Occupations

Science and Health

Psychiatry and Psychology

Analytical, Diagnostic, and Therapeutic Techniques and Equipment

Humanities

length of schooling; life skills; notifiable disease; perception of equity; personal skills; policy environment; racial health inequalities; social gradient in health; social responsibility for health; social stratification; social support; socio-spatial health inequalities; and spatial health disparities.

In addition to increasing the number of documents retrieved on the Virtual Health Library portal, various terms proposed in this study make it possible to retrieve relevant documents in MEDLINE, suggesting that they have the potential to become MeSH descriptors. In fact, the descriptors stemming from this work, such as "public anti-discrimination policies" and "chronic disease indicators," were later included in the MeSH as part of BIREME's collaboration with the NLM for translation of the MeSH.

The inclusion of the new descriptors allows the subject of equity to be more widely represented in the DeCS/MeSH. The fact that these concepts are spread among the branches of the thesaurus' hierarchical tree shows their multidisciplinary or cross-cutting nature. The new equity descriptors are mainly concentrated under "Health Promotion". Indexing articles and other scientific materials with the right descriptors increases specificity in information retrieval, which is a priority for promoting health equity.

Authors' contribution. ACEC, AT and RTM contributed to the development of the methodology and the analysis, proposal and terminological expansion of the DeCs, as well as to writing the manuscript. DG contributed to the revision of the manuscript and OJM to the revision of the DeCS terminology expansion proposal and of the manuscript. All authors reviewed and approved the final version for publication.

Conflicts of interest. None declared.

Declaration. The views expressed in this manuscript are the authors' and do not necessarily reflect the opinion or policy of the RPSP/PAJPH and/or PAHO.

\section{REFERENCES}

1. DeCS [Internet]. Health Sciences Descriptors [accessed 15 Feb 2020]. Available at: http://decs.bvsalud.org/E/homepagee.htm.

2. BIREME/PAHO/WHO. Manual de Indexação de Documentos para a Base de Dados LILACS. [Internet] 2008. São Paulo.
Availableat:http://metodologia.lilacs.bvs.br/download/P/LILACS-4ManualIndexacao-pt.pdf

3. Pan American Health Organization. 29th Pan American Sanitary Conference. $69^{\text {th }}$ Session of the Regional Committee of WHO 
for the Americas. Washington, D.C.: PAHO; 2017. [accessed 5 Mar 2020]. Available at: https://iris.paho.org/bitstream/handle/10665.2/49170/CSP296-eng.pdf?sequence=1\&isAllowed =y

4. Pan American Health Organization. Strategic Plan of the Pan American Health Organization 2020-2025. 57 ${ }^{\text {th }}$ Directing Council. $71^{\text {st }}$ Session of the Regional Committee of WHO for the Americas; Washington, D.C.: PAHO; 2019. [accessed 6 Mar 2020]. Available at: https://iris.paho.org/bitstream/handle/10665.2/51599/CD57OD359-e.pdf?sequence $=1 \&$ is Allowed $=y$

5. BIREME/PAHO/WHO. Health equity, information dissemination and $\mathrm{PAHO} / \mathrm{WHO}$ technical cooperation. Bulletin No. 19: 2018. São Paulo. [accessed 27 Feb 2020]. Available at: https://boletin.bireme. org/en/2018/04/27/health-equity-information-disseminationand-pahowho-technical-cooperation/

6. Mújica OJ, Moreno CM. From words to action: measuring health inequalities to "leave no one behind". Rev Panam Salud Publica. 2019;43:e12. Available at: https://iris.paho.org/ handle/10665.2/49755

7. Bouchard L, Albertini M, Batista R, de Montigny J. Research on health inequalities: A bibliometric analysis (1966-2014) [published correction appears in Soc Sci Med. 2015 Nov;145:140]. Soc Sci Med. 2015;141:100-108. Available at: https://doi.org/10.1016/j. socscimed.2015.07.022

8. Brazil. Ministry of Health. Análise de situação de saúde/ Ministério da Saúde, Universidade Federal de Goiás. Brasília, 2015. [accessed 4 Mar 2020]. Available at: http://bvsms.saude.gov.br/bvs/ publicacoes/asis_analise_situacao_saude_volume_1.pdf

9. Arcaya MC, Arcaya AL, Subramanian SV. Inequalities in Health: definitions, concepts and theories. Glob Health Action. 2015;8:27106. Available at: https://doi.org/10.3402/gha.v8.27106

10. cdc.gov [Internet]. Sources for data on social determinants of health. Atlanta: Centers for Disease Control and Prevention; 2018 [accessed 5 Mar 2020]. Available at: https://www.cdc.gov/socialdeterminants/ data/index.htm

11. Fundação Osvaldo Cruz [Internet]. Glossário. Rio de Janeiro: Fundação Osvaldo Cruz; 2010 [accessed on 4 Mar 2020]. Available at: https://portal.fiocruz.br/noticia/glossario

12. World Health Organization [Internet]. Health Promotion Glossary. Division of Health Promotion, Education and Communication; Geneva: WHO; 1998 [accessed 4 Mar 2020]. Available at: https:// www.who.int/healthpromotion/about/HPR\%20Glossary\%20 1998.pdf

13. Pan American Health Organization [Internet]. Portal for the Equity List and Knowledge Network. Washington, D.C.: PAHO; 2018 [accessed 5 Mar 2020]. Available at: http://equity.bvsalud.org/ glossary

14. Pan American Health Organization [Internet]. Health Determinants and Inequalities; Washington, D.C.: PAHO; 2012 [accessed 4 Mar 2020]. Health in the Americas. Available at: https://www.paho.org/salud-en-las-americas-2012/index.php? option=com_content\&view $=$ article\&id $=58$ :health-determinantsand-inequalities\&Itemid $=165 \&$ lang $=e n$

15. World Health Organization [Internet]. Gender, equity and human rights. Glossary of terms and tools. Geneva: WHO; 2011 [accessed 6 Mar 2020]. Available at: https://www.who.int/ gender-equity-rights/knowledge/glossary/en/

16. World Health Organization [Internet]. A Glossary of Terms for Community Health Care and Services for Older Persons. Ageing and Health Technical Report. Geneva: WHO Centre for Health Development; 2004 [accessed 5 Mar 2020]. Available at: https:// apps.who.int/iris/bitstream/handle/10665/68896/WHO_WKC_ Tech.Ser._04.2.pdf?sequence $=1 \&$ isAllowed $=y$

17. World Health Organization. Handbook on health inequality monitoring: with a special focus on low- and middle-income countries. Geneva: WHO; 2004. [accessed on 5 Mar 2020]. Available at: https://apps.who.int/iris/bitstream/handle/10665/ 85345/9789241548632_eng.pdf?sequence $=1$

18. World Health Organization [Internet]. Health Impact Assessment (HIA). Glossary of Terms used [accessed 18 Jan 2020]. Geneva: WHO; 2018. Available at: https://www.who.int/publications/m/ item/glossary-of-terms-used-for-health-impact-assessment-hia

19. World Health Organization [Internet]. Health Systems: Equity [accessed on 5 Feb 2020]. Available at: https://www.who.int/ healthsystems/topics/equity/en/

20. Observatory onHealth Inequities[Internet]. RiodeJaneiro:PortalDSS Brasil; 2012 Mar 27. [accessed 5 Mar 2020]. Available at: http:/ /dssbr org/site/2012/03/observatorio-sobre-iniquidades-em-saude/

21. Lobo A, Mateus S. Validity and Reliability of an Equity in Health Care Scale Improvement. SAGE Open. 2013 Oct 7. Available at: https://doi.org/10.1177/2158244013506716

Manuscript received on 3 April 2020. Accepted for publication, following review, on 26 May 2020.

\section{Nuevos Descriptores en Ciencias de la Salud para clasificar y recuperar información sobre equidad}

RESUMEN

Palabras clave
El vocabulario Descriptores en Ciencias de la Salud (DeCS) establece un lenguaje único y común que permite la organización y facilita la búsqueda y recuperación de la literatura técnica y científica en salud disponible en las fuentes de información de la Biblioteca Virtual en Salud. El DeCS, creado por el Centro Latinoamericano y del Caribe de Información en Ciencias de la Salud (BIREME), un centro especializado de la Organización Panamericana de la Salud/Organización Mundial de la Salud (OPS/OMS), es la traducción y la extensión del vocabulario Medical Subject Headings (MeSH), mantenido por la National Library of Medicine de los Estados Unidos. BIREME, en coordinación con expertos de América Latina y el Caribe, ha incluido en el DeCS los temas de equidad, género, etnicidad y derechos humanos — temas transversales en el marco programático de la cooperación técnica de la OPS/OMS - para garantizar una mejor recuperación y uso de la información y evidencia científica relacionadas a estos temas. El objetivo de este artículo es describir el método de revisión terminológica del DeCS e informar los resultados obtenidos y los impactos de la ampliación terminológica en el área de equidad, que comprendió la inclusión de 35 nuevos descriptores.

\section{Equidad; sistemas de información; Medical Subject Headings; práctica clínica basada en la evidencia; acceso} a la información. 